\title{
Educação física na Perspectiva do Ensino Médio e DA EdUCAÇÃo DE JOVENS E AdULTOS(AS): IMPRESSÕES NA Formação Inicial de Professores(AS)
}

\author{
PHYSICAL EDUCATION IN HIGH SCHOOL AND IN YOUTH AND \\ ADULTHOOD EDUCATION: IMPRESSIONS FROM TEACHER EDUCATION
}

DOI: 10.23926/RPD.2526-2149.2020.v5.n2.p870-888.id804

\section{Carlos Átila Lima dos Santos}

Instituto de Educação Física e Esportes da Universidade Federal do Ceará (UFC) carlosatilalima@gmail.com

\section{Priscila Rose de Oliveira Alves}

Instituto de Educação Física e Esportes da Universidade Federal do Ceará (UFC) priscilarose1988@gmail.com

\section{Luciana Venâncio}

Instituto de Educação Física e Esportes da Universidade Federal do Ceará (UFC) Programa de Pós-Graduação em Educação Física da Universidade Federal do Rio Grande do Norte (UFRN) luvenancio@ufc.br

\section{Luiz Sanches Neto} Instituto de Educação Física e Esportes da Universidade Federal do Ceará (UFC) Programa de Pós-Graduação em Educação Física da Universidade Federal do Rio Grande do Norte (UFRN) luizsanchesneto@ufc.br
Resumo: Neste artigo, apresentamos impressões sobre a inserção da Educação Física no Ensino Médio e na Educação de Jovens e Adultos(as) (EJA), a partir das narrativas dos(as) alunos(as) que frequentam a Educação Básica. O objetivo é identificar a importância e o sentido atribuído à Educação Física pelos(as) estudantes do Ensino Médio e da EJA. Analisamos qualitativamente as falas dos(as) estudantes utilizando da pesquisa interpretativa com entrevistas semiestruturadas. Como resultado, foi possível identificar simbolismos marcantes nas falas dos(as) estudantes, como o conteúdo esportivo ser predominante nas aulas, vivências no formato simplista de "rolar a bola" e a ausência do componente curricular na EJA. Como contraponto às impressões, consideramos a importância da formação inicial no processo de legitimidade e o posicionamento do(a) professor(a) perante a comunidade escolar para estabelecer o espaço da Educação Física no currículo escolar e como prática significativa ao(à) aluno(a).

Palavras-chave: Educação Física. Ensino Médio. Educação de Jovens e Adultos(as).

\begin{abstract}
In this article, we present impressions about the insertion of Physical Education in High School and in Youth and Adulthood Education (EJA), from the narratives of students who attend Basic Education. The objective is to identify the importance and meaning attributed to Physical Education by High School and EJA students. We analyzed the students' statements qualitatively using interpretive research with semi-structured interviews. As a result, it was possible to identify striking symbolisms in the students' statements, such as sports content being predominant in classes, experiences in the simplistic format of "rolling the ball" and the absence of the curricular component in the EJA. As a counterpoint to their impressions, we consider the importance of the teacher education in the legitimacy process and the position of each teacher towards the school community to establish the space of Physical Education in the school curriculum and as an embodied practice to the students.
\end{abstract}

Keywords: Physical Education. High School. Youth and Adulthood Education. 


\section{INTRODUÇÃO}

A promulgação da Lei de Diretrizes e Bases da Educação Nacional (LDB) (BRASIL, 1996) apontou os rumos - até certo ponto progressistas - da escolarização brasileira a fim de implementar novas propostas que estivessem alinhadas ao processo histórico, político e social, dando ênfase na formação do(a) aluno(a) para o exercício da cidadania e qualificação ao campo de trabalho. A LDB estabelece que a Educação Básica é composta pelos seguintes níveis: Educação Infantil, Ensino Fundamental e Ensino Médio. Além disso, posteriormente, o Ensino Fundamental foi ampliado para nove anos. Essa mudança fez com que os(as) alunos(as) passassem mais tempo frequentando o espaço escolar, demonstrando que a formação básica apenas estaria completa ao término do Ensino Médio, diferente das propostas anteriores que traziam outros pontos de terminalidade (SILVA; VENÂNCIO, 2005). A Educação Básica não é a única modalidade existente na LDB, além dela existe o Ensino Superior, a Educação de Jovens e Adultos(as) (EJA), a Educação Profissional, a Educação Especial, a Educação do Campo, a Educação Indígena e a Educação Quilombola (BRASIL, 1996).

A Educação Física também esteve presente nos dois documentos anteriores da LDB (1961 e 1971) sob manipulações governamentais e atribuições de diversas funcionalidades utilitárias, como a capacitação física dos(as) alunos(as) e como instrumento de preparação para o trabalho (DARIDO, 2012a, 2012b; SILVA; VENÂNCIO, 2005). Até a publicação da terceira LDB, a Educação Física era considerada uma atividade de cunho extracurricular, ou seja, não era um componente curricular obrigatório do processo de escolarização (DARIDO, 2012a). Assim, a Educação Física alcançou o status de componente do currículo da Educação Básica na segunda metade da década de 1990; entretanto, essa alteração não resultou em mudanças tão significativas. Por exemplo, a LDB não garantiu as aulas de Educação Física em todos os níveis (Educação Infantil, Ensino Fundamental e Médio), como no caso da Educação Infantil e das séries iniciais do Ensino Fundamental em que, com frequência, as aulas são ministradas por professores(as) formados(as) no curso de Pedagogia (SILVA; VENÂNCIO, 2005). Entretanto, em 2001, houve uma alteração no Art. 26 da LDB, que inseriu a palavra “obrigatória" junto à expressão componente curricular (BRASIL, 1996). De todo modo, a situação de precariedade permaneceu mesmo com essa inserção na legislação. Esse descompasso é indicativo de um problema consistente.

O problema, então, é a falta de reconhecimento dos saberes engendrados pela Educação Física. A Educação Física, como área de conhecimento, lida com questões relativas às dinâmicas da cultura, do movimento, do corpo e do ambiente de forma convergente (SANCHES 
NETO et al., 2013) e, como componente curricular, busca fortalecer a criticidade da sua identidade dentro do contexto escolar na realidade brasileira (SANCHES NETO; BETTI, 2008). Neste artigo, especificamente, levaremos em consideração o nível de Ensino Médio, a modalidade de EJA e os seus entrelaçamentos com o componente curricular Educação Física. Embora a Educação Física seja aparentemente valorizada como componente curricular na área de linguagens, códigos e suas tecnologias em diversas proposições (BRASIL, 1996, 1999, 2018), há precariedade na sua efetiva oferta a todos(as) os(as) estudantes nessas fases da escolarização.

Este artigo abrange essa problemática - situada no contexto de um curso de Licenciatura em Educação Física - e fundamenta-se em uma investigação baseada em narrativas, realizada com estudantes do Ensino Médio e da EJA sobre a sua perspectiva da Educação Física escolar na cidade de Fortaleza. Na sondagem inicial - que realizamos com os(as) estudantes no início do segundo semestre de 2019 - foi apontado que as aulas de Educação Física no Ensino Médio são organizadas, dicotomicamente, em teóricas e práticas. Entretanto, as aulas ocorrem somente quando os(as) alunos(as) optam por vivenciar ou por assistir às atividades propostas no contraturno escolar, ou seja, as aulas acabam por tornarem-se optativas e, por vezes, a escola não disponibiliza o espaço, o tempo e o investimento necessários às aulas em virtude do seu foco em exames vestibulares. Esse problema afeta tanto as escolas públicas quanto as empresas educacionais (ou escolas privadas). No caso da EJA, percebemos que a situação se agrava pois, de acordo com os relatos dos(as) estudantes, praticamente não há aulas de Educação Física nessa modalidade de ensino. Ao final daquele semestre, retomamos a interpretação da sondagem com o objetivo de identificar a importância e o sentido atribuído à Educação Física pelos(as) estudantes do Ensino Médio e da EJA.

\section{A Educação Física na Perspectiva do Ensino Médio e da EJa}

O percurso das políticas educacionais brasileiras para o nível do Ensino Médio vem lidando com intensas disputas em seu campo, principalmente devido à intensificação da política neoliberal vigente no país por meio da mundialização do capital com o auxílio da expansão da globalização (STERING; ADAM, 2019). Logo, as escolas, os(as) professores(as), os(as) alunos(as), o núcleo gestor e a comunidade ao entorno escolar têm o desafio de uma construção de forma conjunta de outra identidade para o Ensino Médio (BRASIL, 2006), superando visões elitistas, mercadológicas e tecnocráticas de ensino, voltadas ao "mercado de trabalho" e que aprisionam a escolarização como ensino para o vestibular - ou para o exame nacional do Ensino 
Médio (ENEM). “Assim, nota-se que o processo de ensino e aprendizagem e as questões de conteúdo e métodos de ensino são visivelmente postos em segundo plano" (SOUZA, 2017). No ano de 2016, após o golpe civil que instituiu um novo governo na sociedade brasileira, a tendência conservadora se intensificou e ganhou ascensão, pois as medidas do presidente consistiam em uma agenda neoliberal que acentuava o lucro do capital (OLIVEIRA; ALMEIDA JÚNIOR; GARIGLIO, 2018; STERING; ADAM, 2019). Naquele contexto, o governo federal, por meio do Ministério da Educação (MEC), encaminhou a reforma do Ensino Médio, anteriormente conhecida como Medida Provisória nº 746 (MP 746/16).

A MP 746/2016 alterava o texto da LDB, promovendo alterações na carga horária mínima do Ensino Médio, e apresentava itinerários formativos - para as áreas de linguagens e suas tecnologias, matemática e suas tecnologias, ciências da natureza e suas tecnologias, ciências humanas e sociais aplicadas e formação técnica e profissional - que flexibilizavam o currículo. Desse modo, as disciplinas de Português e Matemática seriam obrigatórias nos três anos do Ensino Médio, haveria o reconhecimento de profissionais com "notório saber" e seria retirada a obrigatoriedade das disciplinas de Artes, Educação Física, Filosofia e Sociologia. Desde a sua promulgação e durante seu processo de tramitação, diferentes entidades que têm ligação com a educação, movimentos sociais, sindicatos, pesquisadores(as) renomados(as), trabalhadores(as) da educação e estudantes manifestaram-se contra a reforma, antecipando os retrocessos que proporcionaria à educação brasileira (BASTOS; SANTOS JÚNIOR; FERREIRA, 2017; OLIVEIRA; ALMEIDA JÚNIOR; GARIGLIO, 2018). A mobilização da sociedade com críticas ao conteúdo da reforma acarretou o recuo do Governo Federal em algumas proposições. Com a homologação da Lei 13.415/2017, que substituiu a MP, foi aprovado o aumento da carga horária destinada à Base Nacional Comum Curricular (BNCC) em $60 \%$ e retomada a obrigatoriedade das disciplinas de Artes, Educação Física, Filosofia e Sociologia (BASTOS; SANTOS JÚNIOR; FERREIRA, 2017; OLIVEIRA; ALMEIDA JÚNIOR; GARIGLIO, 2018).

Com o discurso de "enxugar" o currículo das 13 disciplinas da BNCC do Ensino Médio - pois seriam empecilhos para o processo de aprendizagem - e com a falsa ideia de que os(as) jovens teriam a possibilidade de definir suas trajetórias nessa fase de ensino, a Educação Física virou objeto de embates sobre a sua permanência no Ensino Médio. Isto nos faz refletir sobre quais caminhos levaram o componente curricular a quase ter sido removido do Ensino Médio e a ter a sua obrigatoriedade contestada, permitindo apenas a socialização de modo simplista de seus conhecimentos na Educação Infantil e no Ensino Fundamental (MACHADO et al., 2010). 
A Educação Física escolar forjou inúmeras identidades conforme a época e os interesses políticos de cada governo, sendo que há algumas marcas que ainda são perceptíveis na área até os dias atuais, como uma intensa relação com a saúde e uma forte tendência esportivista. Eram evidentes as características que apontavam o descarte da diversidade dos conhecimentos que os(as) alunos(as) já haviam construído, selecionando de forma elitista os(as) mais competentes na lógica perversa dos conteúdos esportivizados, demonstrando um sistema meritocrático de ensino nas aulas de Educação Física. O conceito de meritocracia é fortemente aliado aos conceitos do neoliberalismo e sua política de Estado mínimo (LIBÂNEO; OLIVEIRA; TOSCHI, 2011), ou seja, o atendimento dessas demandas nas aulas expõe o caráter de atividade utilitária da Educação Física para fins de preparar os(as) estudantes ao "mercado de trabalho". Essa preparação também consistia em preparar fisicamente os indivíduos com o propósito de desenvolver aptidões necessárias à produtividade fabril. Nesse sentido, os resquícios da escravidão negra e da "escravidão econômica" na Educação Física ainda precisam ser reconhecidos com profundidade (SANCHES NETO; OYAMA, 1999).

Apesar de ocorrerem alinhamentos da educação às políticas neoliberais, muitos esforços foram mobilizados com a intenção de ampliar a cientificidade na Educação Física com influências de outras áreas de conhecimento e o aporte das ciências humanas (BRASIL, 2006; NUNES; RÚBIO, 2008). Esse processo é decorrente da crise de identidade, que ocorreu a partir dos anos 1980, e a Educação Física começa a se incomodar explicitamente com o lugar incômodo que ocupa perante as outras disciplinas mais valorizadas. Contudo, a partir da década de 1990, com as grandes reformas educacionais brasileiras alinhadas aos interesses internacionais do mercado capitalista, a educação passa a ser interpretada como um produto (ou como commodities) e, logo, mudanças e reformulações seriam necessárias. Ocorreram esforços coletivos de professores(as) em estimular o diálogo e construir novas possibilidades para a Educação Física na Educação Básica, atentando aos conteúdos e aos conhecimentos dos(as) alunos(as), além de buscar uma legitimidade para o componente curricular. Esse novo projeto - tido como inovador - consistia em alinhar a criticidade e o mundo do trabalho ao contexto dos elementos culturais - brincadeira, capoeira, circo, dança, esporte, ginástica, jogo, luta etc. - almejando potencializar sentidos para os(as) alunos(as) acerca do "por quê?" as aulas de Educação Física serem relevantes no Ensino Médio.

Essa ressignificação também foi possível a partir do momento em que as vozes dos(as) estudantes foram postas em evidência, garantindo um espaço crítico de fala e possibilitando uma escuta sensível, desenvolvendo modos significativos a partir dos desejos compartilhados 
e as relações com os saberes dos(as) alunos(as), demonstrando que são os(as) protagonistas do seu próprio processo de aprendizagem (VENÂNCIO, 2019). É nesse sentido que se torna pertinente a Educação Física como componente curricular na Educação Básica, assim como as demais disciplinas, a despeito da visão estereotipada que a comunidade escolar tem sobre a área. Por isso, torna-se primordial que práticas inovadoras sejam registradas - como a produção de materiais que promovam a visibilidade das aulas, projetos e vivências desenvolvidas durante o ano letivo e além dos muros das escolas - para que professores(as) e familiares identifiquem a complexidade dos saberes construídos nesse processo.

Com a contrarreforma do Ensino Médio temos a expressão de uma radicalização das hierarquias dos saberes escolares e a manifestação clara de que determinados conhecimentos valem muito mais do que outros. Isso porque no bojo desta contrarreforma determinadas disciplinas (Matemática e Língua Portuguesa) que já gozavam de alto status curricular ganham ainda mais importância e reconhecimento pedagógico (OLIVEIRA; ALMEIDA JÚNIOR; GARIGLIO, 2018, p. 28).

Apesar dos esforços, ainda há discussões sobre as práticas associadas ao laissez-faire, principalmente aquelas caracterizadas como "rolar a bola". São situações em que os(as) professores(as) resumem as aulas a observar os(as) alunos(as) fazendo atividades que eles(as) mesmos(as) escolheram, sem qualquer processo mediado de significação para aquela prática na quadra ou dentro de qualquer outro espaço escolar, diferindo pouco do que os(as) estudantes fazem no recreio ou nos seus horários livres (DARIDO, 2012a). Os efeitos dessas situações geraram nos(as) estudantes reflexões e chavões para as aulas, como o fato das aulas de Educação Física serem apenas "livres", sem alguma sistematização do conteúdo. Assim, as aulas de Educação Física funcionariam apenas para o lazer - sem qualquer pretensão de conceituar o lazer, que é entendido de modo acrítico e no senso comum - e para desestressar os(as) estudantes que estão na rotina dos estudos, sendo que, nessa perspectiva, as aulas de Educação Física não têm relevância para o vestibular ou para o ENEM (SANTOS et al., 2018).

Entretanto, é necessário compreender que a culpabilização das aulas no formato de "rolar a bola" não deve recair no(a) professor(a), mas nos fatores condicionantes dessa ação, como a compreensão da especificidade do componente pelo núcleo escolar e comunitário, além do reconhecimento das contribuições que a Educação Física pode oferecer. A hegemonia do esporte como conteúdo reforçado pelas competições escolares, sem tratamento pedagógico, e as dificuldades dos(as) professores(as) em mediar a dicotomia entre aspectos teóricos e práticos durante as aulas geram distorções em perceber a incidência de diferentes saberes, segundo Machado et al. (2010), acentuando os fatores que não devem ser descartados para compreender o desinvestimento pedagógico. Conforme apontam as Orientações Curriculares para o Ensino 
Médio (BRASIL, 2006), a Educação Física tem seu lugar de legitimidade na compreensão e discussão - juntos aos(às) jovens - dos valores e significados que dizem respeito às práticas corporais dos sujeitos, que remetem ao seu mundo, seus vínculos socioculturais, preconceitos, sentimentos etc.

\begin{abstract}
O que se espera é que os alunos do ensino médio tenham a oportunidade de vivenciarem o maior número de práticas corporais possíveis. Ao realizarem a construção e vivência coletiva dessas práticas, estabelecem relações individuais e sociais, tendo como pano de fundo o corpo em movimento. Assim, a ideia é de que esses jovens adquiram maior autonomia na vivência, criação, elaboração e organização dessas práticas corporais, assim como uma postura crítica quando esses estiverem no papel de espectadores das mesmas. Espera-se, portanto, que os saberes da Educação Física tratados no ensino médio possam preparar os jovens para uma participação política mais efetiva no que se refere à organização dos espaços e recursos públicos de prática de esporte, ginástica, dança, luta, jogos populares, entre outros (BRASIL, 2006, pp. 224-225).
\end{abstract}

Já a EJA, conhecida anteriormente como supletivo, configura-se pelos sujeitos que não tiveram a garantia da continuidade ou o acesso aos estudos no Ensino Fundamental e no Ensino Médio na idade convencional (BRASIL, 1996). Cabe às instituições de ensino assegurar as oportunidades educacionais adequadas para essa população, conforme as suas condições de vida e de trabalho. A partir das Diretrizes Curriculares e Operacionais da EJA (BRASIL, 2000, 2010), há pontuações sobre as fixações de idade mínima para o ingresso na modalidade e para a realização de exames, quantidade mínima de carga horária em cada nível de ensino e os formatos da EJA em EAD (Ensino a Distância). Embora as escolas demonstrem atenção com a seguridade dos direitos desse público ao acesso, ainda é necessário repensar como construir um currículo que assista a EJA (BÍLIO et al., 2019), uma vez que as atuais mudanças no formato do Ensino Médio infligem na não preservação da EJA devido à extensão da carga horária no ciclo dos três anos. Com a flexibilização do currículo dessa modalidade, a visibilidade que a EJA confere é de um processo abreviado de formação, pela oferta de aulas no horário da noite, aligeirado e sem dificuldades de obtenção de certificação.

\begin{abstract}
Além disso, ainda é possível encontrarmos alunos jovens e adultos aos quais, ao longo de sua trajetória, foram negados os direitos à educação, seja pela oferta irregular de vagas, seja pelas condições socioeconômicas desfavoráveis ou pelas inadequações do sistema de ensino. Essas inadequações, ao longo da história, manifestam-se das mais diferentes maneiras: na organização dos tempos escolares de forma rígida; na construção de normas disciplinares sem a participação dos alunos; na desconsideração dos saberes e das vivências que os alunos constroem fora da escola; na atribuição a cada indivíduo isoladamente da culpa e da total responsabilidade pelos problemas de ensino aprendizagem (BRASIL, 2006, p. 221).
\end{abstract}

Como postulado pela LDB, a Educação Física como componente curricular obrigatório da Educação Básica deve estar inserida durante o processo formativo dos(as) alunos(as) da EJA. 
Apesar disso, o nível de Ensino Médio da EJA possui uma dinâmica de carga horária pequena, pois estabelece como mínimo apenas 1.200 horas (BRASIL, 2000, 2010), que correspondem a um ano e meio. Isto faz com que as escolas "enxuguem" seus currículos, ou seja, optem por gerar a certificação em período mínimo hábil, logo fazendo com que as aulas de Educação Física sejam reduzidas ou inexistam nessa modalidade. Essas decisões são alimentadas, principalmente, por uma leitura perversa e enviesada do próprio documento da LDB, que estabelece a facultabilidade dos(as) alunos(as) às aulas de Educação Física de acordo com as seguintes condições: ser maior de 30 anos de idade, cumprir jornada de trabalho igual ou superior a seis horas, prestar serviço militar ou ser mulher com prole (BRASIL, 1996). Nas propostas anteriores da LDB (1961 e 1971) havia também a opção facultativa às pessoas “fisicamente incapacitadas” e, até 2003, a Educação Física era facultativa no período noturno. "Essas opções de facultabilidade reforçavam as intenções do governo da época de que a Educação Física fosse apenas um instrumento de preparação para o trabalhador" (SILVA; VENÂNCIO, 2005, p. 55). A opção de não apresentar o componente no ensino noturno implicou diretamente na EJA, retirando a sua vigência na modalidade. Assim, grande parte da população que não tinha acesso à disciplina era excluída e privada dos saberes sistematizados da Cultura Corporal de Movimento (SILVA; VENÂNCIO, 2005).

Nos casos onde há a inserção do componente curricular na EJA, o tratamento da Educação Física é como aula opcional, momento de lazer ou de descanso, marginalizando a área no currículo escolar como apontam Carvalho e Camargo (2019). Algumas vezes, a própria formação é um entrave para o reconhecimento das especificidades da modalidade, fazendo com que os(as) docentes em um primeiro contato com a EJA iniciem sua prática pedagógica sem conhecimentos mínimos nem preparo adequado para a intervenção com esses(as) alunos(as). Entretanto, apesar da complexidade do trabalho com a EJA, há inicialmente uma valorização maior da atividade teórica em relação à atividade corporal prática, pois existe o estereótipo e o discurso de que nesse ambiente todos(as) estão satisfeitos com a reprodução do modelo educacional dicotômico, reafirmando que a sala de aula é o local dos pensamentos e a quadra é o espaço físico destinado apenas ao movimento corporal, remetendo ao esvaziamento da noção de complexidade do pensamento e à dualidade do corpo (REIS; MOLINA NETO, 2014). À Educação Física cabe estimular um olhar crítico sobre as práticas corporais presentes na cultura e mundo de trabalho desses(as) alunos(as), ou seja, partir da sua realidade sem atrelar seu discurso aos interesses de preparo do corpo para a jornada de trabalho, afastando-se dos preceitos mercadológicos neoliberais (LIBÂNEO; OLIVEIRA; TOSCHI, 2011). Para isso, é 
necessário que o(a) professor(a) construa coletivamente um espaço reflexivo e crítico com os(as) alunos(as), capaz de amparar e mobilizar novos saberes (REIS; MOLINA NETO, 2014).

\section{Escolhas Metodológicas}

Nossa escolha metodológica foi qualitativa e desenvolvida por meio de uma pesquisa interpretativa das narrativas dos(as) participantes. As narrativas foram construídas a partir de relatos que, por sua vez, foram obtidos por meio de entrevistas. Os relatos dos(as) estudantes configuram-se como uma abordagem concisa para compreender o ambiente escolar a partir das suas vozes como agentes sociais (REIS; MOLINA NETO, 2014). Isso possibilita a interpretação das argumentações a partir de quem está envolvido em cada contexto situado, levando em consideração a subjetividade dos(as) participantes. Trata-se de uma pesquisa desenvolvida a partir dos dados obtidos em uma sondagem, realizada em duas etapas por uma turma de licenciandos(as) na disciplina de Educação Física no Ensino Fundamental e Médio, que é ofertada no sexto semestre letivo do curso, no Instituto de Educação Física e Esportes (IEFES) da Universidade Federal do Ceará (UFC). A disciplina é componente curricular obrigatório do curso de Licenciatura em Educação Física, com carga horária de 64h.

O estudo da EJA não é frequente no currículo (UFC/IEFES, 2013) e a inserção específica da pauta sobre a modalidade ocorre somente por meio de Estágios Supervisionados que correspondem ao Ensino Médio e à EJA. Tendo identificado essa lacuna, a disciplina buscou tangenciar os debates e estudos acerca da inserção do componente curricular na EJA, bem como a importância, a complexidade e a dificuldade da modalidade. Foi proposto aos(às) licenciandos(as) que realizassem uma sondagem em formato de entrevista com alunos(as) da Educação Básica que compunham o Ensino Médio regular e o nível médio da modalidade EJA, frequentadores(as) de escolas públicas e privadas. Participaram da entrevista dois alunos e quatro alunas do Ensino Médio, com faixa etária de 15 a 17 anos, e duas alunas da modalidade EJA, com idades de 23 e 32 anos, totalizando oito participantes. O relato dos(as) entrevistados(as) foi realizado por meio de uma entrevista semiestruturada que partia da pergunta “Como é a sua Educação Física no Ensino Médio?" Durante o processo de discussão, de interpretação e da devolutiva aos(às) participantes, para manter o anonimato, optamos por identificá-los(as) por acrônimos compostos pelas letras iniciais de seus nomes. Todos os cuidados éticos na condução da sondagem para geração dos dados foram previamente realizados. 


\section{Resultados e Discussão}

Mediante a análise das entrevistas dos(as) alunos(as) que frequentam o Ensino Médio na Educação Básica e na EJA, os fragmentos de suas falas nos ajudaram a compreender quais as impressões que trazem da trajetória escolar em meio à Educação Física. A expectativa, com base na literatura consultada, é que "os conteúdos da Educação Física são constituídos a partir de uma multiplicidade de práticas produzidas no interior de contextos culturais diferenciados" (BRASIL, 2006, p. 226). Historicamente, a partir do contexto social das décadas de 1960 e 1970, o país viveu uma longa e intensa ditadura militar até a abertura política dos anos 1980. Durante aquele período, o esporte teve uma ascensão social aguda. O currículo tradicional esportivo tinha ênfase em conteúdos de forma prática, evidenciando ainda mais a separação entre aulas teóricas e práticas (SILVA, 2011), assim como podemos observar no seguinte excerto:

agora falando da minha Educação Física atual, no $2^{\circ}$ ano do ensino médio, tenho aula teórica que é dia de segunda-feira e aula prática que é dia de quinta-feira à tarde, práticas de futsal, vôlei, basquete e handebol (Estudante $\mathbf{L}$ ).

Segundo Darido (2012a), durante a ditadura militar, os governantes usaram do esporte para definir a Educação Física como um sustentáculo ideológico, conferindo êxito ao país e promovendo-o em competições de alto nível, atribuindo orgulho à nação e estimulando a criação de heróis e heroínas esportistas. Essas marcas fizeram com que o esporte fosse definido como uma prática cultural hegemônica na Educação Física escolar, como podemos observar esse tipo de reprodução social na fala dos(as) estudantes:

Minhas aulas a maioria das vezes era ou futebol ou vôlei (Estudante A).

No Ensino Médio é mais a prática de esportes (Estudante $\mathbf{R})$.

Por um lado, o esporte, como prática corporal cultural histórica, não deve ser um conteúdo apartado do Ensino Médio, uma vez que é um fenômeno de grande expressividade e guarnecido de legitimidade social. Por outro lado, também não deve ser uma justificativa per $s e$ da presença da disciplina no currículo escolar. Como consequência da hegemonia esportiva, o(a) docente que não constrói as suas aulas ensinando apenas os esportes e suas destrezas técnicas acaba tendo suas aulas rotuladas como "soltas ou abandonadas" (MACHADO et al., 2010, p. 142). Nesse caso, os temas gerais da escola e os que são específicos da Educação Física ficaram à mercê do sistema reprodutivista da esportivização, sendo que até as práticas de outros conteúdos - como jogos e ginásticas - são transformadas em disputas e torneios com premiações para os(as) “melhores” alunos(as) (BRASIL, 2006). 
Assim, é necessário ultrapassar a normatização hegemônica do trato esportivo nas aulas de Educação Física calcada de forma não pedagógica e desprovida de intencionalidades. Para isso, é necessário estimular os sentidos para que o conteúdo seja pertinente à realidade dos(as) alunos(as) de forma crítica e que não seja tido apenas como um mero espaço esvaziado da "prática pela prática", que esteja apenas destinado a desenvolver futuros(as) atletas, talentos esportivos ou times nas aulas. Para que os significados atribuídos às aulas não sejam conforme relata a Estudante Li:

Broxante! Triste, um pré-falecimento; sabe como é, né (Estudante Li).

Com o tempo a ideia de sistematização das aulas esportivistas foi se dissipando, dando espaço para aulas onde os(as) alunos(as) apenas realizam aquilo que desejavam, fazendo o(a) professor(a) tornar-se apenas um(a) expectador(a) das ações dos(as) estudantes, que é o caso do(a) professor(a) caracterizado(a) por "rolar a bola".

É importante frisar que esse modelo que carece da intervenção sistemática do professor não ocorre exclusivamente nas aulas de Educação Física. Nas outras disciplinas, o professor substitui o "rola bola" por "copie da lousa o exercício tal" ou ainda "abra a página do livro didático e responda as questões". Certamente na Educação Física, essa falta de intervenção é mais evidente, pois não temos à disposição os livros didáticos e também porque o espaço das aulas fica completamente exposto para todos na escola (DARIDO, 2012a, p. 23).

Esse tipo de situação possui características comuns, como o fato da escolha dos(as) alunos(as) durante o momento da aula de alguma atividade de seu interesse, algumas alunas migrarem para a periferia da quadra (OLIVEIRA; DAOLIO, 2014) sem intenções de vivenciar alguma atividade, enquanto outras seguem para o voleibol, e os alunos comumente jogarem futsal e ocuparem todo o espaço principal referente à quadra, durante todo o horário destinado à aula de Educação Física. Uma estudante relatou esse tipo de situação nas suas aulas do Ensino Médio:

E... as aulas de Educação Física no Ensino Médio, lá é... tipo, a gente pode pegar a bola pra fazer o que a gente quiser tipo bola do vôlei, bola do futsal, bola do handebol. E fica lá fazendo o que quiser. [...] O professor não passa uma coisa só em cada dia de Educação Física, ele só deixa você fazer o que você quiser lá (Estudante Am).

Consequentemente, a reprodução desse tipo de ação desencadeia outras problemáticas dentro do que seria uma aula de Educação Física escolar. Uma delas está em não haver uma forma de avaliação coerente, pois o(a) professor(a) não estabelece critérios avaliativos pertinentes. Isto atribui um papel à avaliação apenas de método de obtenção de nota e de aprovação (DARIDO, 2012b); entretanto, avaliar é um processo mais amplo. 
E uma vez por mês tinha um negócio de correr 10 voltas na quadra, só podia andar 3 vezes das 10 voltas. Era nossa nota do mês. Tinha que correr pelo menos 7 voltas, porque cada volta era 1 ponto (Estudante $\mathbf{A}$ ).

O meu é bem diferente. É tipo um circuito doideira, tá ligada? (Estudante Li).

$\mathrm{O}$ que as alunas apresentam nos seus relatos são formas de avaliações que remetem à perspectiva tradicional esportivista da Educação Física, comum na década de 1970. A preocupação estava em analisar os desempenhos baseados nas capacidades físicas, algumas habilidades motoras, de forma que os(as) alunos(as) eram avaliados por testes físicos para obtenção de nota (DARIDO, 2012b). Outra característica destes métodos avaliativos era a inexistência da explicação do porquê deveriam realizar tais "testes" e a não relação com o plano de ensino anual do(a) professor(a) desenvolvido com outros conteúdos, além de não levar em consideração a individualidade de cada aluno(a).

Com o advento dos movimentos renovadores na Educação Física, teorias contemporâneas emergiram para criticar o modelo tradicional avaliativo, principalmente no que diz respeito ao processo quantitativo dos exames, como apontam Venâncio e Sanches Neto (2019). É necessário que os(as) docentes tomem consciência sobre esses processos tradicionais, que são recorrentes, e busquem a mudança dessas práticas - que já se tornaram simplistas - a fim de construírem métodos mais qualificados e progressistas. Os instrumentos e critérios têm um papel importante porque subsidiam o processo avaliativo, possibilitando meios de coleta de informações e de identificação dos saberes de domínio dos(as) alunos(as) (VENÂNCIO, 2019). Um exemplo de proposta de avaliação na Educação Física escolar está nos dez critérios apontados por Sanches Neto e Betti (2008) e por Venâncio e Sanches Neto (2019), que se relacionam com as dimensões dos conteúdos - atitudinal, conceitual e procedimental - e abrangem: (1) assiduidade; (2) participação objetiva; (3) envolvimento subjetivo; (4) atitudes específicas; (5) conhecimento tácito; (6) aproveitamento de demonstrações visuais; (7) procedimentos específicos; (8) conhecimento declarativo; (9) aproveitamento de instruções verbais ou gráficas; (10) conceitos específicos. À luz desses critérios, podemos apontar alguns instrumentos que se coadunam ao tipo de habilidade que se pretende avaliar e que sejam compreensíveis para todos(as) os(as) estudantes, alguns deles são:

\footnotetext{
chamada oral (temática), vivências, observação e registro, análise compartilhada de imagens e vídeos, diálogo e instruções verbais, rodas de conversa, preenchimento coletivo de glossário, análise investigativa e argumentação, debate sobre termos e expressões, experimentação e demonstrações visuais, provas individuais ou em grupos, interpretação de representações gráficas, explicitação e escuta (sensível, atenciosa, rigorosa e criteriosa), síntese (por meio de tabelas, gráficos, figuras, mídias etc.), construção de modelos e maquetes, composição de portfólio em formato de vídeo e autoavaliação (VENÂNCIO; SANCHES NETO, 2019, p. 69).
} 
A avaliação é importante aos(as) alunos(as) porque é uma tomada de consciência sobre seus progressos, suas dificuldades e suas capacidades. Além disso, "avaliar é, então, um processo que se relaciona não só com o esforço do aluno de aprender, mas também com o do professor de mudar suas práticas, caso os alunos apresentem dificuldades de aprendizagem" (DARIDO, 2012b, p. 131).

Na EJA no nível médio é necessário enxergar os determinantes sociais e as dificuldades sociais que os(as) estudantes enfrentaram para chegar ao local de inserção nessa modalidade, ou seja, as suas idiossincrasias e vicissitudes. Há conhecimentos desprezados e relações com os saberes que são negadas para os(as) alunos(as) que frequentam a EJA pelas próprias instituições que a ofertam e, além disso, esses(as) alunos(as) não são sequer ouvidos(as). Ao pensar a Educação Física como um componente curricular que estuda a linguagem corporal, a sua inserção nessa modalidade é amparada legalmente. Todavia, sofre confrontos de sua permanência devido às brechas, que também são baseadas na legislação. As falas das alunas da EJA evidenciam essas brechas:

A gente não tem muito contato com a Educação Física porque estuda à noite (Estudante La).

Fui aluna do EJA durante uns 6 anos e lá a gente não tinha Educação Física (Estudante C).

Devido aos pontos de facultabilidade que são apresentados na LDB, as escolas acabam por retirar o componente Educação Física da EJA, pois, principalmente no ensino noturno, a compreensão das subjetividades é precária. O entendimento é que esses sujeitos são estudantes que optaram por estar nesse turno devido à longa jornada de trabalho, ou que têm prole e, logo, passam o dia com a criança enquanto o(a) companheiro(a) retorna do trabalho, ou que passaram da idade mínima de conclusão na Educação Básica; então, se têm idade acima dos 30 anos não são obrigados(as) a frequentar as aulas. A incoerência é que as aulas não são sequer ofertadas, logo não há qualquer possibilidade de facultar o que inexiste, reforçando ainda mais as desigualdades de acesso à educação e alargando as injustiças sociais. O que ao todo não estabelece uma verdade absoluta, pois a estudante La tem 23 anos, por isso não estaria inserida nessa lacuna quanto à idade, o que parece demonstrar que a escola não leva em consideração a totalidade dos(as) alunos(as), mas, talvez, as condições da maioria.

A pressuposição dessas condições majoritárias reflete os modelos tradicionais de educação, que atendiam os vieses do mercado, excluindo os(as) estudantes de vivenciarem as aulas. No entanto, também é importante que o(a) professor(a) de Educação Física, quando inserido(a) nessa modalidade, busque mobilizar os(as) alunos(as) a participarem das aulas, por 
meio de estratégias pertinentes e que apontem os benefícios e caminhos críticos à aprendizagem (SILVA; VENÂNCIO, 2005).

Geralmente não tem professor e quando tem professor ele dá uma aula bem básica, a gente não tem muito contato (Estudante La).

Quando a estudante La nos aponta a ideia de uma aula básica em que não há muito contato, ela expõe um modelo de aula teórica, ou seja, uma visão que parece ser exclusivamente realizada em sala de aula. A ideia do adjetivo "básica" retrata, por analogia, que uma aula que não seja básica é semelhante àquelas convencionais no espaço da quadra, que é o ambiente das aulas completamente práticas. Há um risco ao se propor apenas um único modo de ensino do componente curricular em sala de aula, onde o espaço da quadra seria um local apenas do movimento e a sala um local de pensamento (REIS; MOLINA NETO, 2014).

É necessário contrapormo-nos ao processo de negação das práticas corporais, que desencadeia a recusa do próprio corpo, porque essa dicotomia alimenta a dificuldade em perceber as colaborações dos diferentes saberes na prática docente (MACHADO et al., 2010). Uma outra interpretação possível sobre essa situação seria da pertinência da Educação Física no Exame Nacional para Certificação de Competências de Jovens e Adultos(as) (ENCCEJA), criado em 2002 para ser uma alternativa de certificação da conclusão da EJA nos níveis Fundamental e Médio. Assim como no ENEM, o ENCCEJA do Ensino Médio é estruturado em áreas do conhecimento - linguagens, códigos e suas tecnologias e redação; matemática e suas tecnologias; ciências humanas e suas tecnologias; ciências da natureza e suas tecnologias - e a Educação Física faz parte da área do conhecimento de linguagens, códigos e suas tecnologias. No material didático proposto para essa grande área do conhecimento, a Educação Física "deve ser abordada como ciência que estuda as manifestações da linguagem corporal” (BRASIL, 2002, p. 54). Ao ser inserida nos exames, cabe-nos realizar uma (auto)crítica à nossa prática docente, sobre como esses processos avaliativos quantitativos influenciam metodologias de ensino e podem restringir as ações do(a) professor(a) ao destinar o conhecimento das práticas corporais apenas nas bases conceituais que facilitem a realização dos exames. Quando indagadas sobre o que pensam da inserção da Educação Física, as mesmas alunas relatam os seguintes pontos:

A parte dos esportes, sempre gostei muito de esportes, mas nunca pratiquei muito (Estudantes La).

[...] eu acho ela (Educação Física) muito importante na nossa vida, porque nos mostra novos caminhos e abre a nossa mente para uma perspectiva de vida melhor. Eu lembro da época que praticava quando fazia o Ensino Médio em escola regular e amava praticar. [...] Seria bem legal se o programa pudesse incluir essa modalidade para os 
alunos, pois é uma forma de tirar os jovens e até mesmo os adultos de práticas erradas (Estudante C).

Há uma prevalência do "discurso das práticas esportivas como solução para problemas de saúde, uso de drogas e outras mazelas da sociedade" (BRASIL, 2006, p. 231), à medida que essa visão hegemônica ainda parece reverberar nas impressões das estudantes. É necessário compreender que o esporte, ao ser inserido na EJA, não deve estar vinculado à preparação corporal para as jornadas de trabalho dos(as) alunos(as) trabalhadores(as); mas isso não significa, também, que os saberes propostos em aula devam estar separados da realidade do mundo do trabalho dos(as) estudantes (REIS; MOLINA NETO, 2014). Para isto, é preciso esforços para reforçar a permanência da Educação Física no currículo da EJA, pensando nas suas contribuições aos saberes que os(as) alunos(as) podem construir e ressignificar durante as aulas, além de colaborar com a legitimidade da área, confrontando estereótipos alusivos à aula como um momento "livre" para os(as) estudantes "descansarem e brincarem" sem um propósito pedagógico. Outrossim, também não cabe definir uma aula exclusivamente teórica que negue as vivências nas práticas corporais.

\section{CONSIDERAÇões FinaIS}

$\mathrm{O}$ estudo permitiu que identificássemos fortes impressões dos(as) estudantes sobre o que está sendo - bem como do que não está sendo - a Educação Física escolar. As suas principais argumentações nos mostraram que ainda há dificuldades em legitimar e definir para os(as) alunos(as) qual a importância do componente curricular em sua trajetória escolar no Ensino Médio, seja na Educação Básica regular ou na modalidade de EJA. Além disto, também nos permitiu apontar que algumas práticas tradicionais continuam sendo reproduzidas nos espaços escolares, como a hegemonia do esporte como conteúdo, as práticas de "rolar a bola", aulas exclusivamente teóricas em sala de aula na EJA e a difícil mediação entre a teoria e a prática. Por essa lógica, compreendemos que não cabe responsabilizar os(as) professores(as), mas identificar fatores - como sua própria experiência na formação inicial - que podem determinar a reprodução de uma identidade profissional única para o trabalho docente na Educação Básica, rejeitando a experimentação de práticas mais inovadoras (MACHADO et al., 2010). Há um agravante ainda maior quando evidenciamos a EJA na formação inicial, pois não há aprofundamento sobre essa modalidade e não há contextualização sobre os sujeitos jovens, adultos(as), idosos(as), pessoas em cumprimento de medidas socioeducativas e de todo o processo de intergeracionalidade presente na EJA (CARVALHO; CAMARGO, 2019). 
É necessário levar em conta as condições da vida desses sujeitos como estudantestrabalhadores(as): são pessoas que precisam acordar cedo, muitos(as) dependem de transporte coletivo para se deslocarem, moram longe da escola e/ou do trabalho - em alguns casos estão desempregados(as) e têm a sua luta pela sobrevivência dificultada. Pensando nisso, o desempenho físico-esportivo dos(as) estudantes não é o objetivo mais importante a ser perseguido, o que não significa negar essa dimensão da aprendizagem dos elementos culturais, assim como muitas outras, destinando-a apenas ao cunho teórico (REIS; MOLINA NETO, 2014). É preciso refletir criticamente sobre a autonomia da escola na construção do Projeto Político Pedagógico (PPP) junto com a comunidade escolar, sendo o momento necessário para estabelecer os pontos importantes ao desenvolvimento da escola de acordo com a sua realidade. Entretanto, em alguns espaços escolares o PPP não apresenta forte significância, pois não há a elaboração coletiva e colaborativa do documento, recorrendo a modelos de instituições superiores (SILVA, VENÂNCIO, 2005). Consideramos que a Educação Física deve fazer parte ativa do processo de construção do PPP, cabendo ao(à) professor(a) comprometer-se a colaborar nesse espaço de embates, podendo contribuir para garantir a inserção do componente curricular na EJA. As contribuições de registros das ações podem convencer a comunidade escolar da importância em oportunizar os saberes da Educação Física, mesmo com os aspectos limitantes da legislação (SILVA; VENÂNCIO, 2005; VENÂNCIO; DARIDO, 2012).

Como possibilidades para estudos futuros, ressaltamos também que é necessário repensar como a Educação Física estará inserida no novo formato do Ensino Médio; se será oferecida apenas no primeiro ano e, depois, será apresentada somente àqueles que escolherem em seu itinerário a área de linguagens, códigos e suas tecnologias. Além de pensar como funcionará a sua inserção nos exames avaliativos do Ensino Médio e da EJA - ENEM e ENCCEJA - e como se posicionará perante a continuidade do projeto mercadológico neoliberal de educação. À guisa de conclusão, cabe-nos questionar: Como a mudança do Ensino Médio irá infringir no ensino noturno? Já que a carga horária do Ensino Médio será ampliada, a solução tornar-se-á impossibilitar a oferta do Ensino Médio no horário noturno, atingindo principalmente a EJA? Sugerimos um esforço coletivo dos(as) professores(as) e dos(as) pesquisadores(as) em construir cotidianamente a legitimidade da área como prática crítica que compreende as diferenças e a realidade dos sujeitos que a constituem - a fim de enfrentar os ditames de um projeto conservador e neoliberal que, cada vez mais em tempos de (des)governo autoritário e antidemocrático, assolam os espaços escolares e demandam a criticidade no trabalho docente com a Educação Física no Ensino Médio e na EJA. 


\section{REFERÊNCIAS}

BASTOS, R. S.; SANTOS JÚNIOR, O. G.; FERREIRA, M. P. A. Reforma do ensino médio e a educação física: um abismo para o futuro. Motrivivência, Florianópolis, v. 29, n. 52, pp. 38-52, set. 2017.

BÍLIO, M. G. P.; OLIVEIRA, N. M; CAMPOS, M. G.; GOMES, E. C. Educação de jovens e adultos na perspectiva de duas escolas em Cuiabá. Revista Prática Docente, Confresa-MT, v. 4, n. 2, pp. 834-851, jul./dez. 2019.

BRASIL. Base nacional comum curricular [versão homologada]. Brasília:

MEC/Consed/Undime, 2018. Disponível em: 〈http://basenacionalcomum.mec.gov.br〉. Acesso em: 30 mar. 2020.

BRASIL. Diretrizes curriculares nacionais para a EJA. Brasília: CNE/CEB, resolução n ${ }^{\circ} 1$ de 2000.

BRASIL. Diretrizes operacionais para a educação de jovens e adultos. Brasília: CNE/CEB, resolução no 3 de 2010.

BRASIL. Lei $n^{\circ}$. 9.394, de 20 de dezembro de 1996. Lei de diretrizes e bases da educação nacional. Brasília: Diário Oficial da União, 20 de dezembro de 1996.

BRASIL. Livro do professor - ensino fundamental e médio: linguagens, códigos e suas tecnologias - língua portuguesa, língua estrangeira, educação artística e educação física. Brasília: MEC: INEP, 2002.

BRASIL. Ministério da Educação. Orientações curriculares para o ensino médio: linguagens, códigos e suas tecnologias. Brasília: Secretaria de Educação Básica/MEC, v.1, 2006.

BRASIL. Parâmetros curriculares nacionais - ensino médio. Brasília: Secretaria de Educação Média e Tecnológica/MEC, 1999.

CARVALHO, R. M. A.; CAMARGO, M. C. S. Formação de professores em educação física e a educação de jovens e adultos. Movimento, Porto Alegre, v. 25, pp. 1-13, 2019.

DARIDO, S. C. Educação física na escola: realidade, aspectos legais e possibilidades. In: Universidade Estadual Paulista (Unesp); Universidade Virtual do Estado de São Paulo Univesp) (Orgs.). Caderno de formação - formação de professores: didática dos conteúdos. São Paulo: Cultura Acadêmica, 2012a, v. 6, pp. 21-33.

DARIDO, S. C. A avaliação da educação física na escola. In: Universidade Estadual Paulista (Unesp); Universidade Virtual do Estado de São Paulo Univesp) (Orgs.). Caderno de formação - formação de professores: didática dos conteúdos. São Paulo: Cultura Acadêmica, 2012b, v. 6, pp. 127-141.

LIBÂNEO, J. C.; OLIVEIRA, J. F.; TOSCHI, M. S. Educação escolar: políticas, estrutura e organização. 10a ed. São Paulo: Cortez, 2011. 
MACHADO, T. S.; BRACHT, V.; FARIA, B. A.; MORAES, C.; ALMEIDA, U.; ALMEIDA, F. Q. As práticas de desinvestimento pedagógico na educação física escolar. Movimento, Porto Alegre, v.16, n. 2, pp. 129- 147, abr./jun. 2010.

NUNES, M. L.; RÚBIO, K. O(s) currículo(s) da educação física e a constituição da identidade de seus sujeitos. Currículo sem Fronteiras, Rio de Janeiro, v. 8, n. 2, pp. 55-77, jul./dez. 2008 .

OLIVEIRA, C. M.; ALMEIDA JUNIOR, A. S.; GARIGLIO, J. A. Educação física escolar, juventudes e processos de escolarização no contexto das "novas" políticas educacionais: perguntas para e com os sujeitos do ensino médio. In: NOGUEIRA, V. A.; MALDONADO, D. T.; FARIAS, U. S. (Orgs.). Educação Física escolar no ensino médio: a prática pedagógica em evidência. Curitiba: CRV, 2018, pp. 17-38.

OLIVEIRA, R. C.; DAOLIO, J. Educação física, prática pedagógica e não-diretividade: a produção de uma "periferia da quadra". Educação em Revista, Belo Horizonte, v. 30, n. 2, pp. 71-94, abr./jun. 2014.

REIS, J. A. P.; MOLINA NETO, V. "Pensei que tava na aula de ciências" ou os significados da educação física na educação de jovens e adultos. Pensar a Prática, Goiânia, v. 17, n. 3, pp. 636-650, jul./set. 2014.

SANCHES NETO, L.; BETTI, M. Convergência e integração: uma proposta para a educação física de $5^{\mathrm{a}}$ à $8^{\mathrm{a}}$ série do ensino fundamental. Revista Brasileira de Educação Física e Esporte, São Paulo, v. 22, n. 1, pp. 5-23, jan./mar. 2008.

SANCHES NETO, L.; CONCEIÇÃO, W. L.; OKIMURA-KERR, T.; VENÂNCIO, L.; VOGEL, A. J. Z.; FRANÇA, A. L.; CORSINO, L.N.; RODRIGUES, J. C.; FREITAS, T. P. Demandas ambientais na educação física escolar: perspectivas de adaptação e de transformação. Movimento, Porto Alegre, v. 19, n. 4, pp. 309-330, out./dez. 2013.

SANCHES NETO, L.; OYAMA, E. R. Da escravidão negra à "escravidão econômica" contemporânea: implicações para a educação física no Brasil. Discorpo, São Paulo, n. 9, pp. 45-71, jul./dez. 1999. Disponível em: <http://cev.org.br/biblioteca/da-escravidao-negraescravidao-economica-contemporanea-implicacoes-para-educacao-fisica-brasil/> . Acesso em: 29 jun. 2020.

SANTOS, A. C.; SANCHES NETO, L.; VENÂNCIO, L.; SILVA, E. V. M. Tematização das questões de educação física no exame nacional do ensino médio: ênfase no corpo, na dança, no esporte e no jogo. Revista Brasileira de Educação Física Escolar, Curitiba, v. 4, n.1, pp. 7-20, mar. 2018.

SILVA, M. E. H. A formação permanente relacional na educação física escolar. Tese (Doutorado em Educação) - Centro de Educação, Universidade Federal da Paraíba, João Pessoa, 2011.

SILVA, E. V. M.; VENÂNCIO, L. Aspectos legais da Educação Física e integração à proposta pedagógica da escola. In: DARIDO, S. C.; RANGEL, I. C. A. (Orgs.). Educação física na escola: implicações para a prática pedagógica. Rio de Janeiro: Guanabara Koogan, 2005, pp. 50-63. 
SOUZA, L. C. A. B. Políticas educacionais e o papel da escola: entre o real e o ideal. Revista Prática Docente, Confresa-MT, v. 2, n. 1, p. 112-120, jan./jun. 2017.

STERING, S. M. S.; ADAM, J. M. A reforma do ensino médio por meio da lei $\mathrm{n}^{\circ}$ 13.415/2017 e seus impactos no ensino médio integrado dos institutos federais. Revista Prática Docente, Confresa-MT, v.4, n.2, pp. 869-886, jul./dez. 2019.

UNIVERSIDADE FEDERAL DO CEARÁ (UFC). Instituto de Educação Física e Esportes (IEFES). Projeto pedagógico do curso de licenciatura em educação física. Fortaleza: Universidade Federal do Ceará, 2013.

VENÂNCIO, L. A relação com o saber e o tempo pedagogicamente necessário: narrativas de experiência com a educação física escolar. Revista de Estudos da Cultura, São CristóvãoSE, v. 5, n. 14, pp. 89-102, maio/ago. 2019.

VENÂNCIO, L.; DARIDO, S. C. A educação física escolar e o projeto político pedagógico: um processo de construção coletiva a partir da pesquisa-ação. Revista Brasileira de Educação Física e Esporte, São Paulo, v. 26, n. 1, pp. 97-109, jan./mar. 2012.

VENÂNCIO, L.; SANCHES NETO, L. Instrumentos e critérios no processo de avaliação em educação física escolar: "errar é humano", mas é fonte de aprendizagem. Instrumento, Juiz de Fora-MG, v. 21, n. 1, pp. 58-73, jan./jun. 2019.

Recebido em: 30 de junho de 2020 .

Aprovado em: 30 de agosto de 2020. 